\title{
Community Service Creating Applied Information System for Managing Inventory on Hotel SWK 95, Surabaya, Indonesia
}

\author{
Alexander Setiawan", Andre Gunawan, Kevin Utomo, and Bernard Yusuf Jioe* \\ Informatics Department, Faculty of Industrial Technology, Petra Christian University, \\ Jl. Siwalankerto No.121-131, Surabaya 60236, Indonesia.
}

\begin{abstract}
In the ever-expanding digital information era, hotels in particular Hotel SWK 95 should start using information technology to help hotel operations to operate maximally. Hotel SWK 95 has an information system for booking rooms and others but Hotel SWK 95 does not have information system to manage Inventory like pillow, blanket, etc. So here the author has compiled and made an inventory information system to meet the needs of the Hotel SWK 95. The information system that the authors created can help in the inventory arrangements, especially as laundry systems and vendors anywhere that the hotel use to wash the laundry and schedule when the estimated laundry should be taken. And also the status, quantity, and history of the circulation of existing goods.
\end{abstract}

Key words: Circulation of goods, hotel, information system, laundry, manage inventory, report, supply chain, warehouse management

\section{Foreword}

\subsection{Background}

In the ever-expanding digital information era, businesses need to start using the existing information technology to be competitive in their business world. In this paper the author is focusing on the world of hotel business. Hotel is a fast growing business industry and every people that is traveling need them. Business process of hotel that becoming bigger need some support from the ever-growing information system for ease of use and optimization of the business process that is happening in that hotel. Many process of hotel business that is helped by information system such as booking a room can be made online, check in and check out process using computer to avoid data errors, and also up to the hotel room keys

\footnotetext{
${ }^{*}$ Corresponding author: alexander@petra.ac.id bernard.jioe@gmail.com
} 
now many are made of cards that provide security to the visitors of the hotel and also reduces the manufacturing of key costs for the hotel itself.

In this activity the author focuses on Hotel SWK 95 located on Siwalankerto Street 95, Siwalankerto, Wonocolo, Surabaya City, East Java, Indonesia. The hotel has used the information system to make room reservations, check in and check out, and other hotel business process. But the authors found that the Hotel SWK 95 has not used the information system to manage the data items or inventory that exist in the hotel.

\subsection{Problem formulation}

The author finds some problems that occur in Hotel SWK 95 because Hotel SWK 95 still use manual recording without using information system for data goods or the inventory. Among others are:

i) Risk of data loss Because of using stock cards.

ii) The stock cards are fragmented so that the management is hard to see their own inventory reports.

iii) No information on the condition or condition of the goods, such as being washed or damaged.

\subsection{Objectives and benefits}

The purpose of this activity are:

i) Assist the hotel in handling the inventory circulation process.

ii) Create an information system for the hotel.

iii) Completing the coursework for the course Applied Information Systems.

The benefits of this activity are:

i) Hotels can operate better with the help of the information system that the author made.

ii) The hotel management can view inventory reports such as the number and condition of their goods more easy.

iii) Employees can view, manage, and use information systems that authors made to help their tasks related to inventory management.

\section{Method or execution method}

\subsection{Activity plan}

\subsubsection{Schedule of community service:}

i) First visit on 20 February 2017

ii) Second visit on 20 March 2017

iii) The visit on 10 April 2017

iv) The visit on 17 April 2017

v) The visit on 24 April 2017 


\subsubsection{Description of activities}

i) Background and objectives of the activity: Hotel SWK 95 still manage all the needs of the warehouse manually, through the products, it is expected that the hotel SWK 95 can manage the warehouse to better purposes and concise. Preparation (including surveys and preparation done in class during the course support Service-Learning): Conducting Survey two times with the introduction of interest while recognizing the need Hotel SWK 95 against the application to be made.

ii) The next visit is a consultation if information systems created in accordance with the client desires.

iii) Implementation of activities: February 20, 2017 to June 9, 2017

\subsection{Identity of the target of community service}

i) Target community name and location: Hotel SWK 95, Siwalankertostrett 95, Siwalankerto, Wonocolo, Surabaya City, East Java. Number of community/communities served: 20 (Total-party management and existing employees).

\section{Theoretical basis}

\subsection{HTML5}

HTML5 is a natural evolution of earlier version of HTML and strives to reflect the need of both current and future Web sites. It inherits the vast majority of features from its predecessor, meaning that if you coded HTML before HTML5 came on the scene, you already know a lot of HTML5. This also means that much of HTML5 works in both old and new browsers; being backward compatible is a key design principle of HTML5 [1].

HTML5 supports cross platform, designed to display web pages on a PC, or a Tablet, a Smartphone, or a Smart TV. HTML5 is been a working draft and some browser designers and websites are already adopting HML5 elements. HTML5 also support location based services open formats such as Scalable Vector Graphics (SVG), open XML file formats and high quality graphics [2].

\subsection{CSS3}

The use of Cascading Style Sheets (CSS) makes web design flexible and scalable. CSS allows you to separate your website's content from its layout: a core concept of progressive enhancement [3].

CSS3 is more powerful than earlier versions of CSS and introduces numerous visual effects, such as drop shadows, text shadows, rounded corners, and gradients. [1]

\subsection{Javascript}

JavaScript is a computer language which is used in most of the web browsers like Chrome, Firefox, Netscape, and Safari. It is mainly used for establishing interactions via interfaces. The end of scenarios can be seen where the usage of Javascript on websites was found [4].

Early JavaScript concentrated on client-side form validation and working with images on webpages to provide rudimentary, although helpful, interactivity and feedback to the 
visitor. When a visitor to a website filled in a form, JavaScript instantly validated the contents of the web form rather than making a round-trip to the server. Especially in the days before broadband was pervasive, preventing the round-trip to the server was a great way to help applications seem a little quicker and more responsive and it still is [5].

\subsection{SQL server 2012}

SQL Server 2012 is Microsoft's latest cloud-ready information platform. Organizations can use SQL Server 2012 to efficiently protect, unlock, and scale the power of their data across the desktop, mobile device, data center, and either a private or public cloud. It provides organizations with mission-critical performance and availability, as well as the potential to unlock breakthrough insights with pervasive data discovery across the organization [6].

\subsection{XAMPP}

XAMPP is a small and light Apache distribution containing the most common web development technologies in a single package. Its contents, small size, and portability make it the ideal tool for students developing and testing applications in PHP and MySQL [7].

\subsection{Supply chain management system}

Supply Chain Management is defined as "the integration of key business processes from end user through original suppliers that provide products, services, and information that add value for customer and other stakeholders [8].

\subsection{Warehouse management system}

A warehouse management system (WMS) is a database driven computer application, to improve the efficiency of the warehouse by directing cutaways and to maintain accurate inventory by recording warehouse transactions. The systems also direct and optimize stock based on real-time information about the status of bin utilization [9].

\subsection{Laundry management system}

The Laundry Management System is designed for any Laundry firm to replace their existing manual, paper based system. The new system is in form of an e-registration system to control the following; customer information, products, services, users, carts and receipt. Since the existing system makes use of tedious administrative tasks, lots paper work and time, in which full information cannot be gotten from busy customers [10].

\section{Result and discussion}

The results of the activities of the author is a program or information system that is useful to help the inventory adjustment in accordance with that requested by the management Hotel SWK 95. The program or information system that the author made is a web-based, therefore to use it, it requires a browser such as Google Chrome, Mozilla Firefox, or others. Here is an explanation of the program and also how to use the information system that has the author created. 


\subsection{Index Page or Home}

This page contains the main menus provided by this information system, when there is a reminder of laundry to be taken today, and also the overall inventory report along with the existence of the goods. In pie-chart shown stated that $100 \%$ of existing inventory $31.9 \%$ were in the warehouse, $39.3 \%$ were in the House Keeping, and $28.7 \%$ are being washed or laundry. Report this allows the handling inventory management, can be seen in Figure 1.

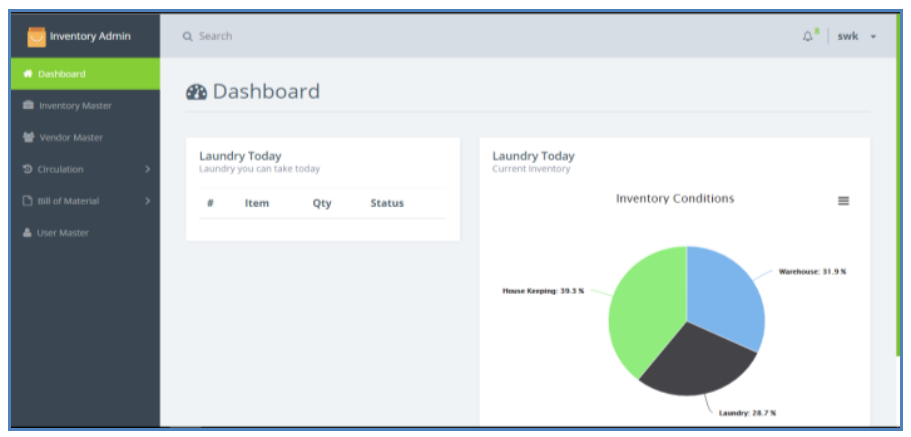

Fig. 1. Dashboard.

\subsection{Inventory Master Page}

This page contains the details of the items in the hotel such as the number and where the goods are located, can be seen in Figure 2.

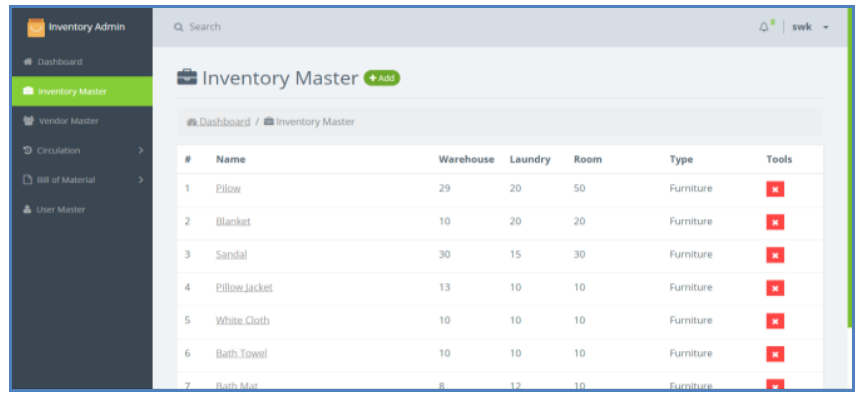

Fig. 2. Inventory master.

Next is when the user presses the add button then the user will go to the Add Inventory Item, where the user can enter the name of the goods, type of goods, quantity of goods in the warehouse, room and laundry service, can be seen in Figure 3. 


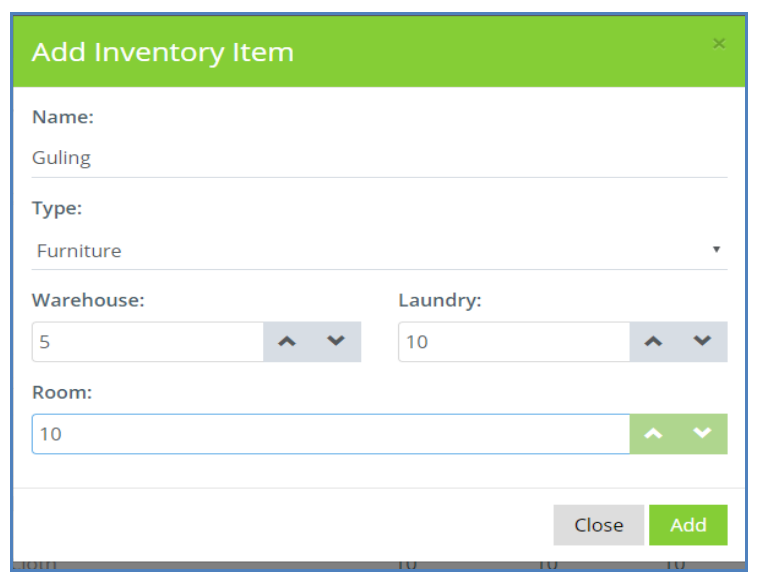

Fig. 3. Add inventory item.

\subsection{Vendor Master Page}

In the Vendor Master page there is a list of places where hotels do laundry, or also make repair such as sewing and so on, can be seen in Figure 4. Data recorded are the names and contacts of these vendors. To add a new vendor can press the Add button there, can be seen in Figure 5. To edit can tap or click the name of the vendor that you want to edit, can be seen in Figure 6.



Fig. 4. Vendor. 


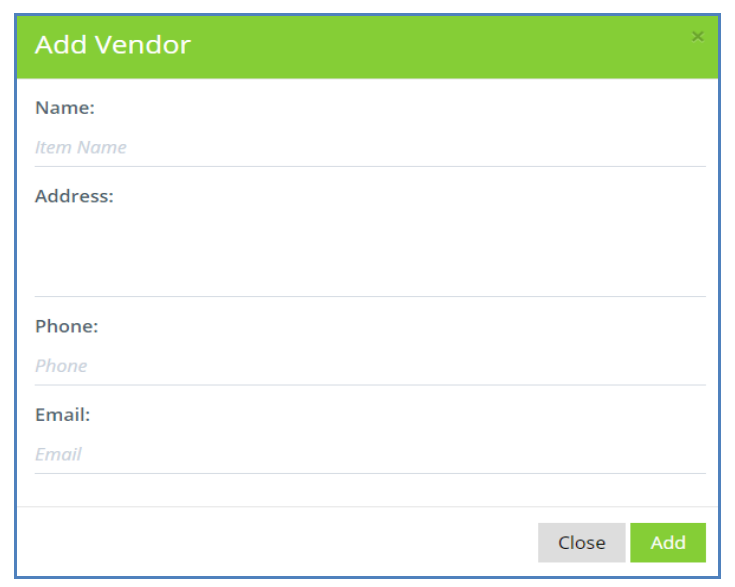

Fig. 5. Add vendor.

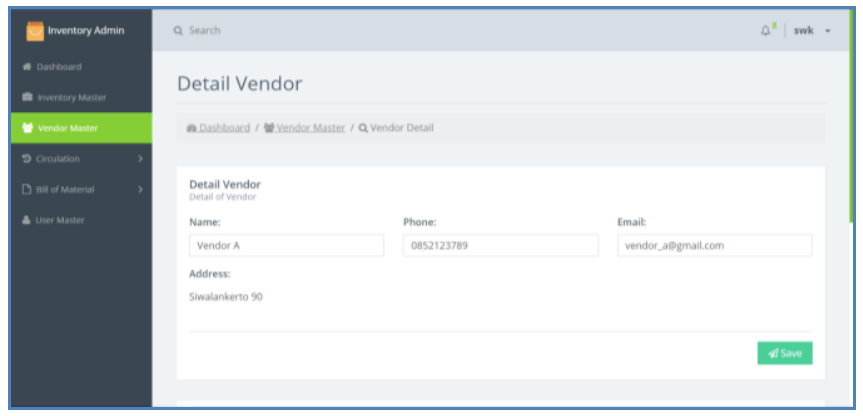

Fig. 6. Edit vendor.

\subsection{Circulation page}

\subsubsection{Overview}

On this page the user can see the status and the date of a transaction that changed circumstances or the amount of goods, can be seen in Figure 7. To see more detail can press the desired number of transactions it will be taken to a page detail overview. For status can also press a button that is received when the goods have been confirmed up to the hotel, can be seen in Figure 8.

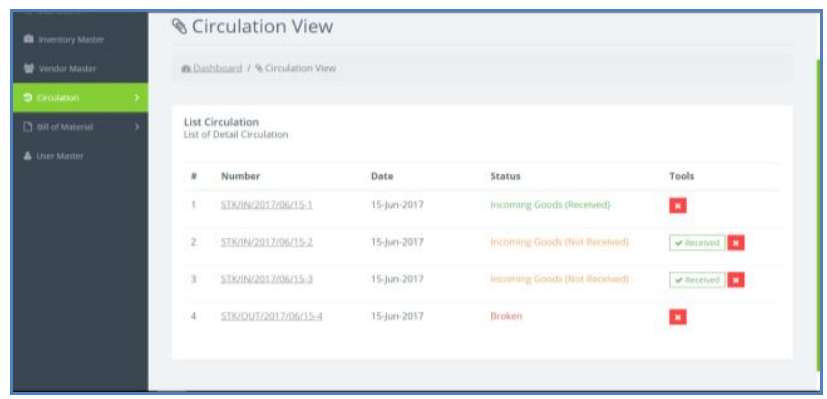

Fig. 7. Overview. 


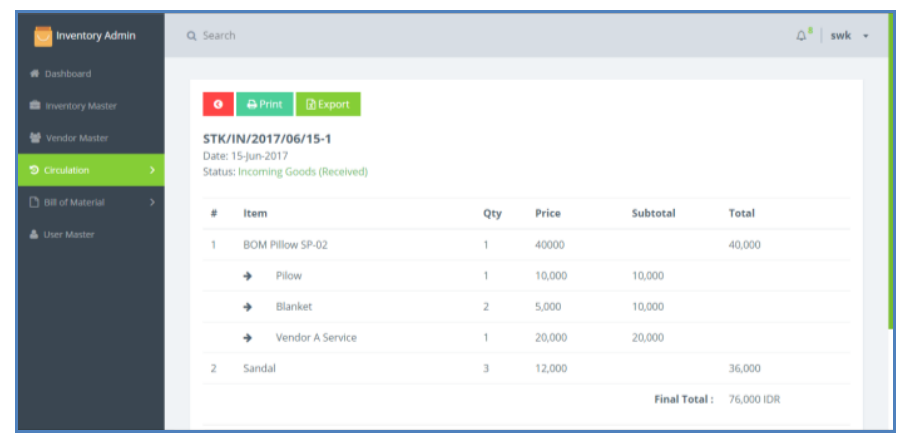

Fig. 8. Detail overview.

\subsubsection{Incoming goods}

In this page the user can enter the data items that will come from the expected date and time the goods will arrive as well as any items that will come along with the number and the price and also from vendors which. Also provided facilities to write notes or a special note for this upcoming items. Can be seen in Figure 9 and Figure 10.

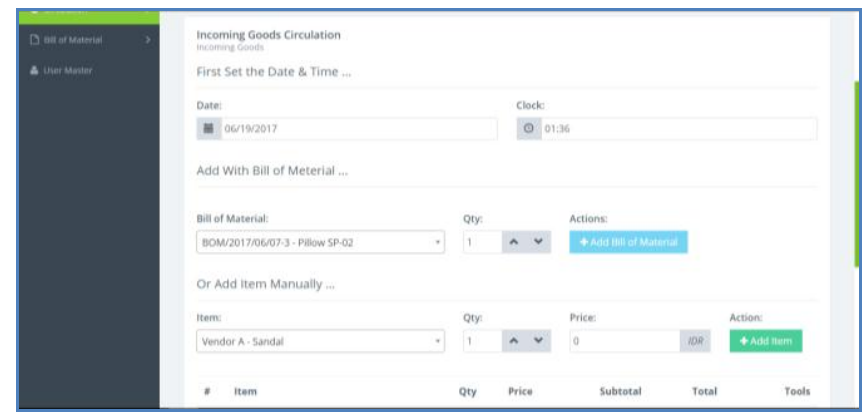

Fig. 9. Incoming goods



Fig. 10. Incoming goods continued.

\subsubsection{Lost items}

On this page the user can enter data items that is lost or damaged or reduced in value due to other reasons. The data recorded is the reason why it is reduced in value, the date and time, what items and their numbers. And also if there is a special note can be written in the notes section. It can be seen in Figure 11. 




Fig. 11. Lost items.

\subsubsection{Maintenance}

On this page the user can see what items are in the process of laundry or other repairs. Along with a status whether the process has been completed or not, can be seen in Figure 12. To add a list of maintenance, the user can press the blue plus button located to the right of the screen. Users will find pages Add Maintenance to be filled in based on the existing data such as item name, number, date, etc., can be seen in Figure 13.

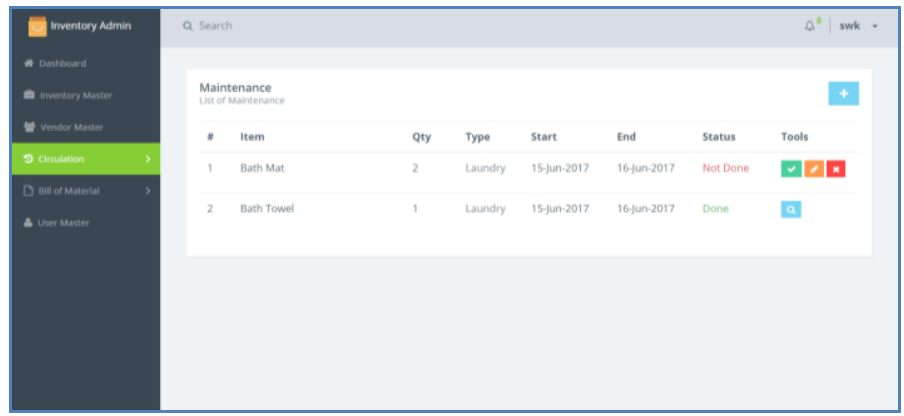

Fig. 12. Maintenance.

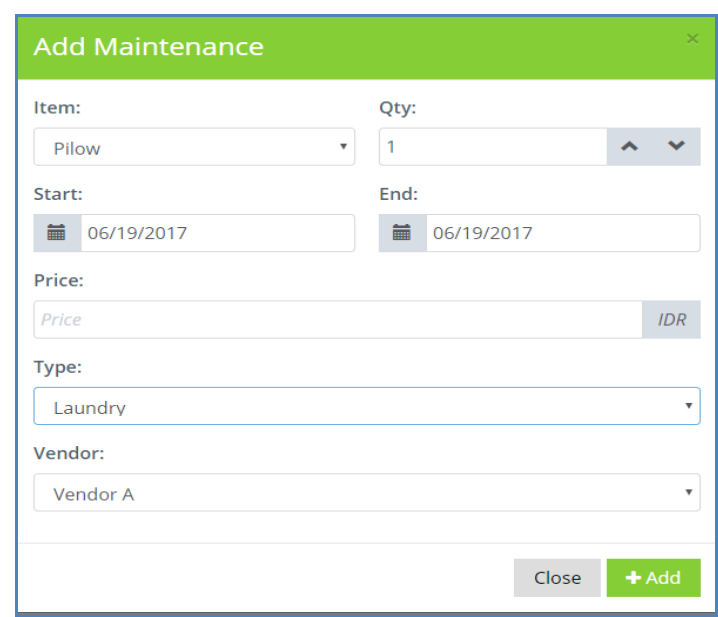

Fig. 13. Add maintenance. 


\section{Conclusion}

From writing the above, it can conclude that the work system inventory information for Hotel SWK 95 have met the hotel demand for a information system that can manage the flow of goods like laundry and other items that is needed for the hotel to perform their service and the authors hope that the hotel management information system which has been created by the author can be useful and facilitate business processes that take place in the hotel. The hotel management to focus on the problem laundry or laundry frequent errors or delays due to the recording process is still manual, the authors make a feature that helps solve the problem like helping the hotel to manage their goods with ease, the hotel can track their circulation or flow of goods around and manage when some item need to be repaired or even if the item is lost the hotel can track it as why that item is lost.

Gratitude and praise the author pray to Allah Almighty God because without God's blessing, the author may not be able to complete the Service Learning this well and without any problems. The author also wishes to thank profusely to the Hotel SWK 95 who had been going to be a Service Learning and set aside some time for the authors. The authors also thank the other parties who may not be mentioned who have supported the author in this Service Learning activities.

\section{References}

1. Ch. Rajesh, K.S.V.K. Srikanth. International Journal of Computer Science and Information Technologies, 5, 2:2408-2412 (2014).

http://ijcsit.com/docs/Volume\%205/vol5issue02/ijcsit20140502328.pdf

2. S.C. Baker. Journal of Library \& Information Services in Distance Learning, 8, $3-$ 4:118-136 (2014). https://www.tandfonline.com/doi/abs/10.1080/1533290X.2014.945825

3. E. Castro, B. Hyslop. HTML5 and CSS3: visual quick start guide. 7th ed. USA: Peachpit Press (2012). p. xvi. https://books.google.co.id/books?id=WbQAAAAQBAJ\&printse $=$ frontcover\&dq $=$ E. + Castro,,+ B.+ Hyslop,+ HTML5 + and + CSS3 $\& \mathrm{hl}=\mathrm{en} \& \mathrm{sa}=\mathrm{X} \& \mathrm{ved}=0 \mathrm{ahUKEwj} 2$ 7HT0MHdAhWH6Y8KHTcjBrIQ6AEIKTAA\#v= onepage\&q=E. $\% 20$ Castro $\% 2$ C $\% 20$ B. $\% 20$ Hyslop $\% 2$ C $\% 20$ HTML $\% 20$ and $\% 20$ CSS3 $\& \mathrm{f}=$ false

4. Md. Z. Ahmed. International Journal of Computer Science and Mobile Computing, 3, 6:193-207 (2014). https://www.ijcsmc.com/docs/papers/June2014/V3I6201456.pdf

5. S. Suehring. Javascript step by step. 3rd ed. USA: Microsoft Press. p. 3 (2013). https://books.google.co.id/books?id=L-$\underline{\mathrm{rMgEACAAJ} \& d q=S .+ \text { Suehring }+ \text { Javascript }+ \text { Step }+ \text { by }+ \text { Step } \& h l=e n \& s a=X \& v e d=0 a h U}$ KEwigpab 0cHdAhVKv48KHaH-CQAQ6AEIKTAA

6. R. Mistry, S. Misner. Introducing Microsoft SQL Server 2012. Washington: Microsoft Press (2012). p. 3. http://download.microsoft.com/download/f/f/6/ff62cae0-ce38-42289025-

fbf729312698/microsoft_press_ebook_introducing_microsoft_sql_server_2012_pdf.pd $\underline{f}$

7. D.D. Dvorski. Installing, configuring, and developing with XAMPP [Online] from http://dalibor.dvorski.net/downloads/docs/InstallingConfiguringDevelopingWithXAM PP.pdf (2007). [Accessed on 12 February 2017] 
8. V. Misra, M.I. Khan, U.K. Singh. Journal of Strategic Innovation and Sustainability, 64, 4:102-108 (2010).

http://digitalcommons.www.na-businesspress.com/JSIS/MisraWeb.pdf

9. A. Ramaa, K.N. Subramanya, T.M. Rangaswamy. International Journal of Computer Applications, 54, 1:14-20 (2012).

https://pdfs.semanticscholar.org/faff/485f479ec9f8fa0c280a4c1f977697f23ebe.pdf

10. O. Shoewu, N.T. Makanjuola, D.A. Phillips, A. Emmanuel. The Pacific Journal of Science and Technology, 17, 2:197-204 (2016).

http://www.akamaiuniversity.us/PJST17_2 197.pdf 